s Cream, J. J., Gumpel, J. M., and Peachey, R. D. G., Quarterly fournal of Medicine, 1970, 39, 461.

Castanier, J., Hée, P., Lelièvre-Gassin, C., Chevry, A., Annales de Dermatologie et Syphiligraphie, 1967, 94, 379.

Winkelmann, R. K., and Ditto, W. B., Medicine, 1964, 43, 59

- Ansell, B. M., British fournal of Dermatology, 1970, 82, 211 . Investigation, 1968, 19, 437.

10 Cameron, J. S., British Medical fournal, 1970, 4, 285.

\section{Treatment of Carcinoma of the Larynx}

At present there are three main ways of treating carcinoma of the larynx-radiotherapy, ${ }^{1}$ surgery, ${ }^{2-4}$ or both. ${ }^{3}{ }^{5-7}$ Though there is still some debate about the exact place of each of these methods, and in the system of staging these tumours, ${ }^{89}$ highly effective routines of treatment have now been established. The method selected depends on the exact site and extent of the tumour, which may arise on, above, or below the vocal cord. The site of origin is particularly relevant at the upper and lower boundaries of the larynx, where the mucosa merges with that of the pharyngeal floor and trachea, respectively. ${ }^{1}$ Characteristically tumours arising in these regions invade neighbouring compartments slowly, but those which arise even just outside these boundaries may come into the same category as pharyngeal or tracheal tumours, with correspondingly poorer prognoses whatever treatment is used. Thus cancer of the vocal cord, which characteristically manifests itself while tiny (by producing hoarseness) and metastasizing late, is long confined to the cartilaginous box of the larynx and bears a relatively good prognosis, compared to growths near the "escape" points of the larynx.

Cases of laryngeal cancer may be classified into three illdefined categories, which merge imperceptibly. In the first are those cases suitable for curative, primary teleradiotherapy. These include small glottic carcinomas, which do not "fix" the vocal cord. A programme of radiotherapy usually lasts for six weeks; the patient receives 6,000 rads, and this may yield a five-year cure rate of over $90 \%$. Another group that responds well to radiotherapy are women, who characteristically are cured by radiotherapy even when the tumour is advanced. The third, and more debatable, group are patients in whom the intralaryngeal soft tissues are extensively invaded, though neither destruction of the cartilage nor spread to the regional lymph nodes has occurred.

When radiotherapy fails, surgical rescue is possible. If still confined to the vocal cord the tumour can be removed by laryngofissure ${ }^{10-12}$-a limited operation carried out through the laryngeal cartilage or, if more extensive, by total laryngectomy. The latter leaves the patient with an end trachosteome, and oesophageal speech thereafter is possible using regurgitated air.

In the second category are those patients for whom either surgery or radiotherapy can offer only limited benefit. These are patients with some destruction of the laryngeal cartilages, spread of tumour outside the larynx, or involvement of the lymph nodes. Because of the limitations of either kind of treatment used on its own there is now widespread enthusiasm for preoperative irradiation, ${ }^{13-19}$ in a dose of $1,500-4,000$ rads (over from two to four weeks), followed by elective surgery four weeks or so later. This programme seems particularly effective, since after a full course of radiotherapy persistent tumour may be difficult to detect, unless it was initially advanced. For this reason laryngectomy, with or without a block dissection of the regional lymph nodes in the neck, is done no matter what the immediate outcome of the radiotherapy has been. The purpose of the preliminary radiotherapy is to reduce bulk and viability of the tumour without jeopardizing the subsequent healing of any operation wounds.

Into this relatively tidy regimen intrudes the conception of partial laryngectomy, ${ }^{20-30}$ in which large fragments of the larynx are removed. Block dissection of the lymph nodes may be combined with this and a laryngeal airway is reconstructed from the remains, ${ }^{30-32}$ though inevitably this is distorted and inefficient. Broadly speaking these procedures are most applicable to patients in the first category, and therefore compete directly with radiotherapy. Moreover, the delicate repair of the air and food passages is best done on unirradiated tissues, and hence radiotherapy and partial laryngectomy are mutually exclusive. The excellence of the radiotherapy services in the United Kingdom and the problems of aspiration following this type of operation have prevented its gaining in Britain the widespread popularity achieved in the United States. Nevertheless, the choice may be difficult, since partial laryngectomy offers the prospect of retaining a normally produced, albeit, husky voice-which is not the case when radiotherapy has failed and hence has made laryngectomy necessary.

Finally, patients in the third category include those with gross spread of cancer into the neck, involving the carotid tree and cervical spine, with lymph nodes fixed to adjacent tissues as well as distant metastases. ${ }^{1}$ Palliative radiotherapy, tracheostomy, feeding gastrostomy, analgesics, tranquillizers, and cytotoxics may offer these unfortunate patients with essentially terminal disease a small measure of comfort.

Lederman, M., fournal of Laryngology and Otology, 1970, 84, 867.

LeJeune, F. E., Laryngoscope, 1951, 61, 488

${ }^{3}$ Leroux-Robert, J., Annals of Otology, Rhinology and Laryngology, 1956, $65,137$.

Quinn, H. J., jun., Southern Medical fournal, 1964, 57, 1107.

Biller, H. F., Ogura, J. H., Davis, W. H., and Powers, W. E., Laryngoscope, 1969, 79, 1387.

- Goldman, J. L., and Silverstone, S. M., Transactions of the American Academy of Ophthalmology and Otolaryngology, 1961, 65, 496.

Hendrickson, F. R., and Liebner, E., Annals of Otology, Rhinology and Laryngology, 1968, 77, 222.

* American Joint Committee for Cancer Staging and End Results Reporting, Cancer of the Larynx. Chicago, 1962.

International Union against Cancer. T.N.M. Classification of Malignant Tumours. Geneva, 1968.

10 Broyles, E. N., Southern Medical fournal, 1949, 42, 825.

1 Thomson, S. C., British Medical fournal, 1912, 1, 355.

12 Thomson, S. C., British Medical fournal, 1921, 1, 921.

13 Goldman, J. L., Silverstone, S. M., Rosin, H. D., Cheren, R. V., and Zak, F. G., Laryngoscope, 1964, 74, 1111.

it Powers, W. E., and Ogura, J. H., Archives of Otolaryngology, 1965, 81, 153.

15 Powers, W. E., fournal of the Canadian Association of Radiologists, 1965, 16, 217.

16 Powers, W. E., in Proceedings, Fifth National Cancer Conference, p. 461. Philadelphia, Lippincott, 1965.

7 Skolnik, E. M., Tenta, L. T., Comito, J. N., and Jerome, D. L., Annals of Otology, Rhinology and Laryngology, 1966, 75, 336.

18 Skolnik, E. M., Soboroff, B. J., Tenta, L. T., Saberman, M. N., and Jones, H. C., Transactions of the American Academy of Ophthalmology and Otolaryngology, 1968, 72, 937.

19 Strong, E. W., et al., Cancer (Philadelphia), 1966, 19, 1509.

20 Alonso, J. M., Transactions of the American Academy of Ophthalmology and Otolaryngology, 1947, 51, 633.

21 Bailey, B. J., Transactions of the American Academy of Ophthalmology and Otolaryngology, 1966, $70,559$.

2 Conley, J. J., Archives of Otolaryngology, 1959, 69, 700.

${ }_{23}$ Conley, J. J., Archives of Otolaryngology, 1961, 74, 239.

24 Goodyear, H. M., Annals of Otology, Rhinology and Laryngology, 1949, 58,581 .

25 Hautant, A., Annales des Maladies de l'Oreille, du Larynx, du Nez et du Pharynx, 1929, 48, 469.

26 Hautant, A., Traitement du Cancer Endolarynge. Paris, Masson, 1930.

27 Ogura, J. H., and Dedo, H. H., Laryngoscope, 1965, 75, 865.

28 Ogura, J. H., Laryngoscope, 1958, 68, 983.

29 Putney, F. J., and Vicens, E. A., Laryngoscope, 1956, 66, 1041.

30 Reed, G. E., Archives of Otolaryngology, 1967, 86, 318.

31 Quinn, H. J., jun., Laryngoscope, 1969, 79, 1980.

32 Som, M. L., Archives of Otolaryngology, 1951, 54, 524. 